\title{
Nanoscale
}

D) Check for updates

Cite this: Nanoscale, 2019, 11, 15530

\section{Highly sensitive detection of prostate cancer specific PCA3 mimic DNA using SERS-based competitive lateral flow assay $\uparrow$}

\author{
Xiuli Fu, ${ }^{a}$ Jiahui Wen, ${ }^{a}$ Jingwen Li, ${ }^{a}$ Hao Lin, ${ }^{a}$ Yongming Liu, ${ }^{a}{ }^{a}$ Xuming Zhuang, (iD a \\ Chunyuan Tian ${ }^{a}$ and Lingxin Chen (iD *b,c,d
}

Accurate analysis of prostate cancer specific biomarkers plays an important role in the early diagnosis of prostate cancer. Traditional colorimetric lateral flow assay (LFA) has the limitations of low detection sensitivity and qualitative or semiquantitative detection. In this study, we developed a novel surface-enhanced Raman scattering (SERS)-based competitive LFA for the rapid and highly sensitive quantitative evaluation of prostate cancer antigen 3 (PCA3) mimic DNA. Herein, the competitive hybridization interaction with capture DNA between target PCA3 mimic DNA and reporter DNA-labeled SERS nanotags results in a change in the amount of SERS nanotags on the test line. The quantitative analysis of target PCA3 mimic DNA was realized by monitoring the Raman peak intensity of SERS nanotags on the test line. The limit of

Received 8th June 2019, Accepted 22nd July 2019 DOI: $10.1039 / c 9 n r 04864 b$ rsc.li/nanoscale detection of PCA3 mimic DNA was estimated to be $3 \mathrm{fM}$, which is about three orders of magnitude more sensitive than that of a commercially available kit. By combining the outstanding characteristics of the well-established SERS-based competitive strategy and LFA platform, our design has strong potential for the early diagnosis of prostate cancer and other diseases.

\section{Introduction}

Prostate cancer is known as the second leading cause of cancer in males, and more importantly, its incidence and mortality are increasing. ${ }^{1-5}$ The most widely used biomarker for the diagnosis of prostate cancer is prostate specific antigen (PSA). ${ }^{6,7}$ However, its use in early detection of prostate cancer is limited. This is mainly because PSA is produced by the prostate epithelium and paraurethral glands, and is a tissuespecific antigen rather than a cancer-specific antigen. ${ }^{1}$ Many genitourinary diseases such as benign prostatic hyperplasia, prostatitis, acute urinary retention, and various tests related to the prostate (digital rectal examination and prostate resection) can cause elevated levels of PSA, resulting in a high false posi-

\footnotetext{
${ }^{a}$ School of Chemistry and Chemical Engineering, Yantai University, Yantai 264005, China. E-mail: liuyongming100@126.com

${ }^{b}$ CAS Key Laboratory of Coastal Environmental Processes and Ecological Remediation, The Research Center for Coastal Environmental Engineering and Technology, Yantai Institute of Coastal Zone Research, Chinese Academy of Sciences, Yantai 264003, China. E-mail: lxchen@yic.ac.cn

${ }^{c}$ Laboratory for Marine Biology and Biotechnology, Pilot National Laboratory for Marine Science and Technology, Qingdao 266237, China

${ }^{d}$ Center for Ocean Mega-Science, Chinese Academy of Sciences, Qingdao 266071, China

$\dagger$ Electronic supplementary information (ESI) available. See DOI: 10.1039/ c9nro4864b
}

tive rate of the PSA test. ${ }^{1,8,9}$ Besides, if the level of PSA falls in the so-called gray area between 4.0 and $10.0 \mathrm{ng} \mathrm{mL}{ }^{-1}$, it will lead to a high negative biopsy rate. ${ }^{10,11}$ Therefore, there is an urgent need to screen a new specific biomarker for the early diagnosis of prostate cancer. After unremitting efforts, biologists found a new biomarker, prostate cancer antigen 3 (PCA3), which is only expressed in diseased prostate cancer tissues. ${ }^{12}$ According to previous studies, more than $95 \%$ of prostate cancer tissues have high expression of PCA3, and no expression of PCA3 was detected in extra-prostatic tissues. ${ }^{12}$ Thus, PCA3 is an ideal specific biomarker for diagnosing prostate cancer.

The extremely powerful and widely used method for genetic diagnosis and gene expression profiling is the polymerase chain reaction (PCR) technique. ${ }^{13-15}$ Although PCR has high sensitivity, this method is still faced with many instinctive limitations owing to the need for professional technicians, harsh experimental conditions and a long turnaround time, which has seriously restricted their application in lowresource settings. ${ }^{16-18}$ Furthermore, false-positive results may be obtained because the thermal cycling amplification step has a risk of erroneous nonspecific amplification of contaminants. ${ }^{19-21}$ To resolve these issues, various methods have been utilized to detect gene sequences. ${ }^{22-26}$ In particular, a lateral flow assay (LFA) strip has attracted significant interest due to its excellent merits, such as the ease of use, short 
detection time, and low cost, and is easy to expand to mass production. $^{27}$ Until now, LFA has been successfully used to detect virus, ${ }^{28,29}$ antigens, ${ }^{30}$ nucleic acids ${ }^{31}$ and proteins. ${ }^{32}$ For example, an LFA biosensor based on copper oxide nanoparticles has been developed for rapid and quantitative detection of specific nucleic acids. ${ }^{31}$ A hook-effect-recognizable three-line lateral flow biosensor based on an aptamer was constructed to detect thrombin. ${ }^{32}$ However, it also has some limitations, including quantitative analysis and low sensitivity. ${ }^{33,34}$ In view of the above problems, it is necessary to seek a new quantitative analysis method.

Surface-enhanced Raman scattering (SERS) has been considered a potential alternative due to its extraordinary sensitivity and anti-interference ability. ${ }^{33,35}$ When Raman reporter molecules are adsorbed onto the surface of a SERS substrate, their Raman signals could be greatly increased with an enhancement factor of $10^{6}$ to $10^{14}$ due to electromagnetic and chemical enhancement effects. ${ }^{36-39}$ Until now, various metal materials have been employed as SERS substrates, such as silver, ${ }^{40}$ gold, ${ }^{41}$ or copper. ${ }^{42}$ Among them, AuNPs are the most widely used SERS enhancing agent, owing to their excellent SERS activity, ease of preparation and modification, high specific surface area, controllable size and shape, and good biocompatibility. ${ }^{43}$

Herein, we developed a novel SERS-based competitive lateral flow assay for highly sensitive detection of PCA3 mimic DNA. PCA3 belongs to non-coding RNA, containing about 4000 base pairs; so it is very laborious to sequence the entire RNA information. ${ }^{26}$ To solve this problem, biologists designed noncoding PCA3 mimic DNA based on SELEX-based libraries to identify optimal binding sites. ${ }^{44}$ Studies have shown that PCA3 binding sites are at positions 683 and 735. Accordingly, PCA3 mimic DNA containing 40 base sequences was designed and synthesized, using gold nanoparticles as the SERS substrate, combining the SERS technique and the LFA platform to achieve high sensitivity and high selectivity detection of PCA3 mimic DNA. To the best of our knowledge, this is the first time that SERS has been combined with LFA to detect PCA3 mimic DNA, and this also provides a new idea for the detection of other biomarkers in the future.

\section{Experimental section}

\section{Materials and instruments}

Gold(III) chloride trihydrate $\left(\mathrm{HAuCl}_{4},>99 \%\right)$, sodium citrate tribasic dihydrate, tris(2-carboxyethyl) phosphine hydrochloride (TCEP), $\mathrm{Na}_{3} \mathrm{PO}_{4} \cdot 12 \mathrm{H}_{2} \mathrm{O}$, sucrose, Tween 20, sodium dodecyl sulfate (SDS), sodium chloride $(\mathrm{NaCl})$, saline-sodium citrate (SSC) buffer solution ( $\mathrm{pH}$ 7.0), streptavidin, bovine serum albumin (BSA), TRITON ${ }^{\circledR} \mathrm{X}-100$, and Trizma hydrochloride (Tris-HCl) buffer solution ( $\mathrm{pH}$ 7.0) were obtained from SigmaAldrich (St Louis, MO, USA). Malachite green isothiocyanate (MGITC), phosphate buffer saline (PBS, pH 7.4), and a Quant-iT ${ }^{\mathrm{TM}}$ PicoGreens dsDNA assay kit were obtained from Invitrogen Corporation (USA). The nitrocellulose (NC) membrane attached to a backing card (Hi-flow plus HF180) was purchased from Millipore Corporation (Billerica, MA, USA). Absorbent pads (CF4) were purchased from Whatman-GE Healthcare (Pittsburgh, PA, USA). The target PCA3 mimic DNA and the oligonucleotide probes used in this work were synthesized by Sangon (Shanghai, China). They have the following sequences:

PCA3 mimic DNA: 5'-CTG TGA TGA CAT GAG GCA GCG ACG A GA AAA TCT TGA TGG C-3';

Reporter DNA: 5'-GAC GAG AAA ATC TTG ATG GCT TTTTTTTTT TTTTTTTTTT - $\left(\mathrm{CH}_{2}\right)_{6}-\mathrm{SH}-3^{\prime}$;

Capture DNA: 5'-GCC ATC AAG ATT TTC TCG TCG CTG CCT CAT GTC ATC ACA G-biotin-3';

Control DNA: 5'-AAAAAAAAAAAAAAAAAAAA-biotin-3'.

Non-complementary DNA: 5'-GCC TCA ATA AAG CTT ACC TTC C TG CTT GTG GAA ATC TCT A-3'.

Single-base mismatched DNA: 5'-CTG TGA TGA CAT GAG GCA GCG ACG AGA AAA TGT TGA TGG C-3' (the underlined G base is the mismatched base).

Distilled water was purified by using a Milli-Q water purification system (>18.2 M 2 , Millipore Corporation, Billerica, MA, USA) and all chemicals used in this study were of analytical reagent grade.

UV-visible absorption spectra were recorded using a Thermo Scientific NanoDrop 2000/2000C spectrophotometer (USA). Dynamic light scattering (DLS) data were acquired using a Nano-ZS90 (Malvern). Scanning electron microscopy (SEM) images were obtained using a JSM-7900F (Japan). A programmable paper cutter ZQ4000 (Shanghai Kin bio Tech. Co., Ltd, China) was used to obtain strips of expected size. Capture and control DNA were fixed on test and control lines, respectively, on the NC membrane with a dispenser (Shanghai Kinbio Tech. Co., Ltd, China). SERS spectra were recorded using a Thermo Scientific RFS100 Raman system; a diode-pumped He-Ne laser with a power of $5 \mathrm{~mW}$ operating at $\lambda=632.8 \mathrm{~nm}$ was utilized as the excitation source.

\section{Preparation of gold nanoparticles (AuNPs)}

AuNPs were prepared by means of the kinetically controlled seed growth method developed by Bastus with slight modifications. $^{45}$ In short, a $75 \mathrm{~mL}$ solution containing $2.2 \mathrm{mM}$ sodium citrate tribasic dihydrate was heated to boiling within $10 \mathrm{~min}$, and then $0.5 \mathrm{~mL}$ of $\mathrm{HAuCl}_{4}$ was added to the flask on boiling. The resulting solution was heated for 15 min constantly, during which time its colour changed from yellow to grey and then to bright red. After that, the temperature of the fabricated gold seed solution was reduced to $90{ }^{\circ} \mathrm{C}$ by cooling at room temperature. Next, $5 \mathrm{~mL}$ of $60 \mathrm{mM}$ sodium citrate tribasic dihydrate and $0.5 \mathrm{~mL}$ of $25 \mathrm{mM} \mathrm{HAuCl}_{4}$ solution were sequentially added to the flask 12 times at 2 min intervals, and its colour changed from bright red to dark red gradually. Herein, the solution was heated for another $30 \mathrm{~min}$ and the temperature was maintained at $90{ }^{\circ} \mathrm{C}$. Finally, the resulting solution was cooled to room temperature and then was stored at $4{ }^{\circ} \mathrm{C}$ in the dark for further use. All the above operations were performed under continuous agitation. All glassware used in the work was cleaned fully with aqua regia $\left(\mathrm{HCl} / \mathrm{HNO}_{3}\right.$, 
v/v $3: 1$ ), rinsed with distilled water, and then oven-dried prior to use. The average size of AuNPs was determined by SEM, UV-vis spectroscopy, and DLS as seen in Fig. S1. $\dagger$ The average diameter of AuNPs was estimated to be 30-40 nm.

\section{Preparation of reporter DNA-conjugated SERS nanotags}

In order to obtain Raman signals, it is necessary to combine Raman reporter molecules on the surface of gold nanoparticles. ${ }^{46}$ Here, MGITC was selected as the reporter molecule. Briefly, $0.5 \mu \mathrm{L}$ of a $10^{-4} \mathrm{M}$ MGITC solution was added to $1.0 \mathrm{~mL}$ of $1 \mathrm{nM}$ AuNP solution and reacted for $0.5 \mathrm{~h}$ under continuous stirring. Then, a thiolated reporter DNA activation experiment was performed as follows: $100 \mu \mathrm{L}$ of $10^{-4} \mathrm{M}$ reporter DNA was mixed with $100 \mu \mathrm{L}$ of $5 \mathrm{mM}$ TCEP in $100 \mathrm{mM}$ Tris- $\mathrm{HCl}$ ( $\mathrm{pH}$ 7.4). The mixture was incubated for $1 \mathrm{~h}$ at room temperature. During this process, disulfide groups on the reporter DNA were activated and changed into free thiol groups. After that, $35 \mu \mathrm{L}$ of the activated reporter DNA was added to $1 \mathrm{~mL}$ of the MGITC-functionalized AuNPs under stirring and the solution was placed in the dark and reacted for $24 \mathrm{~h}$. Herein, the activated reporter DNAs were conjugated on the surface of MGITC-functionalized AuNPs by the formation of $\mathrm{Au}-\mathrm{S}$ bonds. Next, the mixture was incubated by the addition of $2 \mathrm{M} \mathrm{NaCl}$ solution containing $1 \%$ SDS, and allowed to stand for $24 \mathrm{~h}$. Then, the mixture was centrifuged at $7000 \mathrm{rpm}$ for 10 minutes. After removing the supernatant, the remaining red precipitates were washed with 1\% BSA, and then recentrifuged, repeating the above steps twice. Finally, the resulting SERS nanotags were dispersed in $50 \mu \mathrm{L}$ of an aqueous solution containing $20 \mathrm{mM} \mathrm{Na} \mathrm{PO}_{4} \cdot 12 \mathrm{H}_{2} \mathrm{O}, 5 \%$ BSA, $0.25 \%$ Tween 20 , and $10 \%$ sucrose and stored at $4{ }^{\circ} \mathrm{C}$ in the dark.

\section{Preparation of the DNA probe-immobilized lateral flow assay}

The DNA probe was prepared as follows: $200 \mu \mathrm{L}$ of $2 \mathrm{mg} \mathrm{mL} \mathrm{m}^{-1}$ streptavidin were mixed with $200 \mu \mathrm{L}$ of $10^{-4} \mathrm{M}$ biotinylated DNA (capture DNA or control DNA) and the mixture was reacted for $1 \mathrm{~h}$ at room temperature. The generated conjugates were purified by centrifugation with a centrifugal filter (cutoff: 30 000, Millipore) for $30 \mathrm{~min}$ at $8000 \mathrm{rpm}$. The remaining conjugates (capture probe or control probe) were washed three times, and re-dispersed in PBS buffer for further use.

The lateral flow strip consisted of 4 parts: a sample pad, a conjugate pad, an NC membrane with a plastic backing card, and an absorbent pad. The sample pad was pretreated by soaking with $50 \mathrm{mM}$ Tris- $\mathrm{HCl}$ containing $0.25 \%$ TRITON ${ }^{\circledR}$ $\mathrm{X}-100$ and $150 \mathrm{mM} \mathrm{NaCl}$ followed by drying in an oven at $37^{\circ} \mathrm{C}$ for $2 \mathrm{~h}$. The conjugate pad was used with $5 \mu \mathrm{L}$ of SERS nanotags and dried naturally at room temperature. The NC membrane was marked by dispensing streptavidin-biotinylated capture DNA and streptavidin-biotinylated control DNA to form the test line and the control line, respectively. All the components were assembled through overlapping $2 \mathrm{~mm}$ in sequence and the final assembly membrane was cut into $4 \mathrm{~mm}$ wide strips as displayed in Fig. 1A. For quantitative analysis, the strip was dipped into a 96-well ELISA plate containing various concentrations of sample solutions, and the
(A)

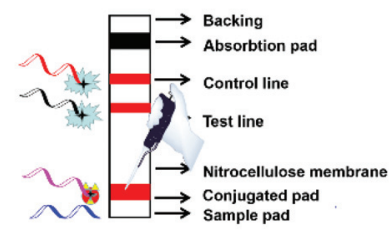

(B)

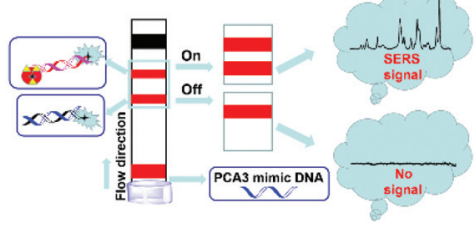

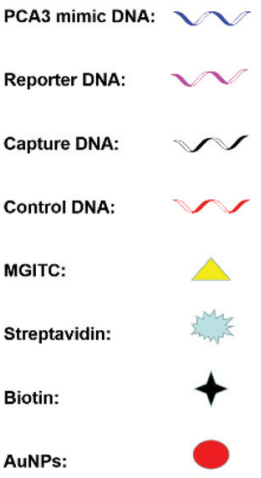

Fig. 1 (A) Illustration of the composition of the lateral flow assay strip for the detection of PCA3 mimic DNA. (B) The principle of measurement for the SERS-based lateral flow assay for the quantification of PCA3 mimic DNA; one colour band was observed on the control line in the presence of the target ("off"), while two colour bands were observed in the absence of the target ("on").

Raman intensity on the test line was measured and analyzed using the Raman instrument.

\section{Results and discussion}

\section{PCA3 mimic DNA assay protocols using SERS-based lateral flow assay}

The operating principle of the SERS-based lateral flow assay strips for PCA3 mimic DNA is shown in Fig. 1. This assay was based on the competition for capture DNA between the reporter DNA functionalized on the SERS nanotags and the target PCA3 mimic DNA. In this system, the capture probe (streptavidin-biotinylated capture DNA) and control probe (streptavidin-biotinylated control DNA) were pre-immobilized on the NC membrane to form the test line and control line, respectively. Reporter DNA functionalized SERS nanotags were dispersed on the conjugate pad, which was designed for complementary hybridization with capture DNA to form a partially double-stranded structure with a redundant single stranded DNA fragment. It should be noted that the T20 DNA spacers in the reporter DNA were used for hybridization with the A20biotinylated control DNA. In this case, whether the target PCA3 mimic DNA exists or not, reporter DNA functionalized SERS nanotags could combine with the control DNA, indicating that the strip worked normally. In the absence of PCA3 mimic DNA, the reporter DNA functionalized SERS nanotags were captured by the capture probe and control probe through complementary base pairing, respectively, resulting in two red lines on the strip (Fig. 1B, "On”, Fig. S2, † “On”). On the other hand, in the presence of PCA3 mimic DNA, the target PCA3 mimic DNA could initiate a toehold-mediated strand displacement reaction, ${ }^{47,48}$ which means that the reporter DNA in the capture-reporter DNA duplex would be displaced by PCA3 mimic DNA. It should be noted that the PCA3 mimic DNA has stronger binding ability with capture 
DNA due to the long complementary sequences (40 complementary base sequences), while reporter DNA has only 20 bases complementary to the capture DNA. Thus, in this way, only one red line was observed on the control line, as shown in Fig. 1B, "Off" and Fig. S2, $\dagger$ "Off". Based on the above, the colour intensity and the Raman intensity of the SERS nanotags on the test line were inversely proportional to the concentration of target PCA3 mimic DNA. The quantitative analysis was realized by measuring the Raman intensity of the SERS nanotags on the test line.

\section{Optical characterization of the SERS nanotags}

The key point of this assay is the synthesis of AuNPs with high Raman enhancement and whether or not the reporter DNA was modified on the surface of AuNPs. To answer the above questions, the UV-vis, DLS and Raman spectra for AuNPs and reporter DNA/MGITC functionalized AuNPs were characterized, respectively. The results displayed that the UV-vis spectra of reporter DNA/MGITC functionalized AuNPs showed a slight redshift from $528 \mathrm{~nm}$ to $530 \mathrm{~nm}$ (Fig. 2A), and the average diameters were changed from $39.95 \mathrm{~nm}$ to $53.04 \mathrm{~nm}$ (Fig. 2B), which was significantly larger than that of AuNPs, indicating successfully combined reporter DNA on the surface of AuNPs. Moreover, the Raman spectra of native AuNPs and reporter DNA/MGITC functionalized AuNPs were recorded (Fig. 2C). From the results, it could be seen that reporter DNA/MGITC functionalized AuNPs presented a strong Raman signal, while the native AuNPs showed no Raman signal.

\section{Optimization of the SERS lateral flow PCA3 mimic DNA assay parameters}

To achieve optimal assay conditions, various experimental factors were investigated including running buffer, the volume of reporter DNA-conjugated SERS nanotags loaded on the conjugate pad and the concentration of the capture probe dispersed on the test line.
(A)

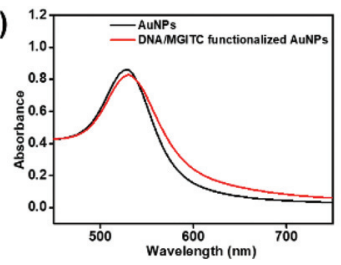

(C)

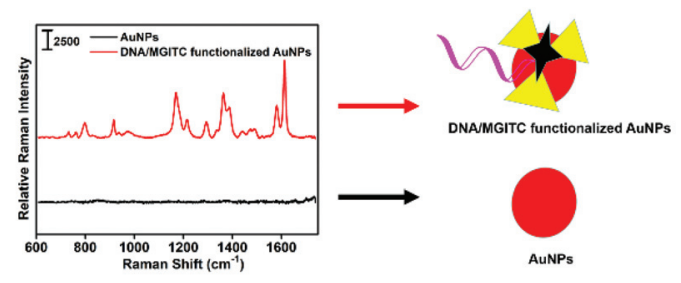

(B)

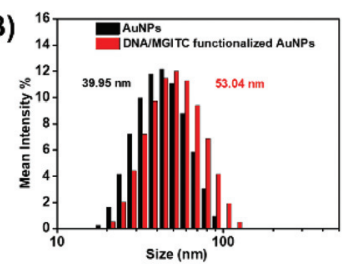

Fig. 2 (A) UV-vis spectra of AuNPs (black line) and DNA-conjugated MGITC-AuNPs (red line). (B) Dynamic light scattering distribution of AuNPs (black column) and DNA-conjugated MGITC-AuNPs (red column). (C) SERS spectra of AuNPs (black line) and DNA-conjugated MGITC-AuNPs (red line).

\section{Effect of running buffer}

As the migration rate of the SERS nanotags and target solution as well as the hybridization efficiency of "reporter DNA conjugated SERS nanotags-capture DNA" and "target DNA-capture DNA" reactions strongly depend on the running buffer, we first studied the performance of the sensor with three different buffer solutions: Tris-HCl, PBS, and SSC. The relationship between different kinds of running buffer solutions and the ratio of peak intensities $\left(I_{0} / I\right)$ was investigated and the corresponding results are shown in Fig. S3A, $\uparrow$ where $I_{0}$ and $I$ are the Raman intensities on the test line at $1613 \mathrm{~cm}^{-1}$ in the absence and presence of PCA3 mimic DNA (100 pM), respectively. It could be seen that the ratio of peak intensities for SSC running buffer was significantly higher than that for the other two buffers. So, the SSC buffer was selected in subsequent assays. In addition, it was known that the SSC buffer concentration is another important factor. To this end, different concentrations of SSC buffer were investigated (Fig. S3B $\dagger$ ). According to the results, $4 \times$ SSC buffer was confirmed as the optimum concentration.

\section{Effect of the volume of reporter DNA-conjugated SERS nanotags}

The Raman signal on the test line directly depends on the amount of captured SERS nanotags, which could affect the sensitivity of our assay. To this end, different volumes of reporter DNA-conjugated SERS nanotags $(1,2,3,4$ and $5 \mu \mathrm{L})$ were added on the conjugated pad. As shown in Fig. S3C, $\dagger$ a maximum ratio of peak intensities was obtained at a volume of $3 \mu \mathrm{L}$. So, $3 \mu \mathrm{L}$ was chosen to be the optimum volume for the SERS nanotags.

\section{Effect of the concentration of capture DNA-conjugated streptavidin}

Different concentrations of the capture probe $(0.0125,0.025$, $0.05,0.075,0.1$ and $0.125 \mathrm{mg} \mathrm{mL}^{-1}$ ) were assayed against solutions containing $100 \mathrm{pM}$ of PCA3 mimic DNA to identify the optimal concentration of capture DNA. As shown in Fig. S3D,$\dagger$ the relative Raman intensity increased with the increased concentration of the capture probe. However, as the concentration of capture DNA exceeded $0.05 \mathrm{mg} \mathrm{mL}^{-1}$, excess hybridization sites were occupied by the reporter DNA-conjugated SERS nanotags. As a result, a significant decrease in the ratio of peak intensities was observed. Therefore, in this work, the optimum capture DNA concentration was $0.05 \mathrm{mg} \mathrm{mL}^{-1}$.

\section{Analytical performance of the SERS-based competitive lateral flow biosensor}

The performance of the SERS-based competitive LFA developed by us for the quantitative analysis of PCA3 mimic DNA was evaluated. Under optimized conditions, we tested different concentrations of target DNA in the range of 0 to $50000 \mathrm{pM}$. From Fig. 3A, it could be seen that as the target DNA concentration increased, more target DNA was able to hybridize with the capture DNA, resulting in fewer reporter DNA-conjugated 

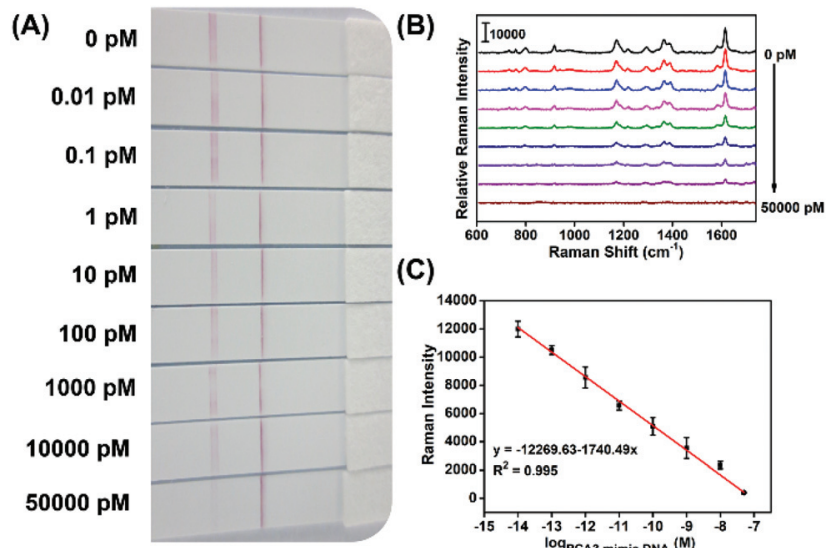

(C)

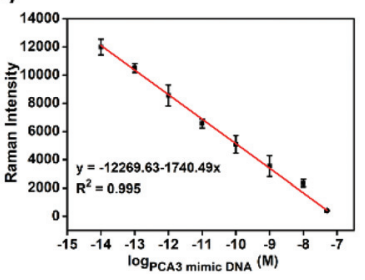

Fig. 3 (A) Typical digital photograph of the SERS-based lateral flow strips after applying different concentrations of PCA mimic DNA (from 0 to $50000 \mathrm{pM}$ ); (B) SERS spectra on the test lines for increasing concentrations of PCA3 mimic DNA (from 0 to $50000 \mathrm{pM}$ ); and (C) the corresponding calibration curve of the test lines for different concentrations of PCA3 mimic DNA (from 0 to 50000 pM). The error bars indicate the standard deviations calculated from five parallel measurements. Assay time: $15 \mathrm{~min}$.

SERS nanotags absorbed on the test line, and the colour on the test line becomes lighter accordingly, and it is difficult to identify colour changes on the test line with the naked eye for a target DNA concentration lower than 1 pM. Consequently, the Raman intensity was concomitantly decreased with the increase in the target PCA3 mimic DNA concentration, as shown in Fig. 3B. Quantitative analysis of target DNA was performed by measuring the Raman signal intensity on the test line. On the basis of the Raman peak intensity of MGITC at $1613 \mathrm{~cm}^{-1}$, the calibration plot for the quantitative evaluation of target DNA was constructed (Fig. 3C), which was employed for the evaluation of the target DNA concentration from an unknown sample. The results indicated that a satisfactory linear relationship was achieved in the range of $0.01-50000$ pM for eight different concentrations. The limit of detection (LOD) was estimated to be $3 \mathrm{fM}$ according to the IUPAC standard method (LOD $=y_{\text {blank }}+3 \mathrm{SD}_{\text {blank }}, y_{\text {blank }}$ is the average signal intensity of the blank and $\mathrm{SD}_{\text {blank }}$ is the standard deviation of the blank measurements). ${ }^{49}$ This value is at least 1000 times more sensitive than that of the conventional PCR method (Fig. S4†). The improvement of the detection sensitivity was attributed to the designed competitive test mode and the significant enhancement provided by the DNA-conjugated SERS nanotags.

To evaluate the potential practicality of the developed SERSbased competitive LFA sensing platform, PCA3 mimic DNA detection in the available human serum was carried out. Here, various concentrations of PCA3 mimic DNA were spiked into commercially available human serum and diluted 5 times with SSC running buffer. The Raman intensity of human serum without PCA3 mimic DNA was used as a blank Raman signal. As shown in Fig. S6, $\uparrow$ the Raman intensity of MGITC at $1613 \mathrm{~cm}^{-1}$ gradually decreased with an increase in the
(A)

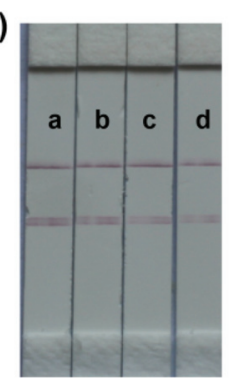

(B)

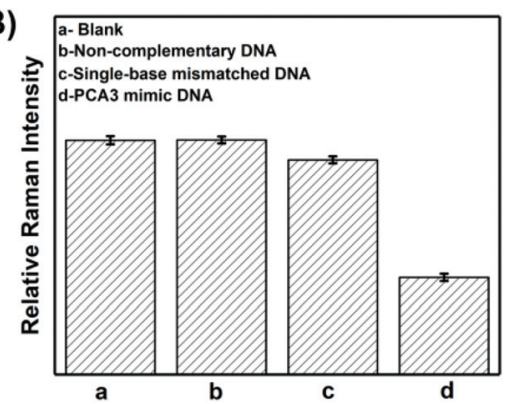

Fig. 4 Selectivity test of the SERS-based LFA. (A) Digital photographic images of four strips and (B) their SERS signal intensity variations for blank, non-complementary, single-base mismatched DNA and PCA3 mimic DNA.

PCA3 mimic DNA concentration range from 0 to $50000 \mathrm{pM}$, and the detection limit was estimated to be $10 \mathrm{fM}$. These results indicated that the developed SERS-based competitive LFA also worked well in biologically relevant media.

\section{Selectivity of the SERS-based competitive lateral flow assay}

To investigate the selectivity of the SERS-based competitive LFA, the non-complementary DNA and the single-base mismatched DNA were examined (Fig. 4). As expected, the Raman intensities for non-complementary DNA, single-base mismatched DNA and the blank on the test line had no significant difference, whereas, in the presence of the same concentration of PCA3 mimic DNA (100 pM), a remarkable Raman intensity decrease is observed. This result suggests the strong binding specificity of our assay toward target PCA3 mimic DNA.

\section{Performance comparison with a commercial assay kit}

To assess the detection sensitivity of our SERS-based competitive LFA, its analytical performance was compared with that of a commercial fluorescence kit (Quant-iT ${ }^{\mathrm{TM}}$ PicoGreen ${ }^{\circledR}$ ) (Fig. S5 $\dagger$ ). For this comparison, seven different concentrations of PCA3 mimic DNA solutions including 0, 0.01, 0.1, 1, 10, 100 and $1000 \mathrm{pM}$ were prepared and tested. The fluorescence assay was preformed according to the manufacturer's protocol. As can be seen from Fig. 5, the minimum detectable concentration of PCA3 mimic DNA using the commercial fluorescence

(A)

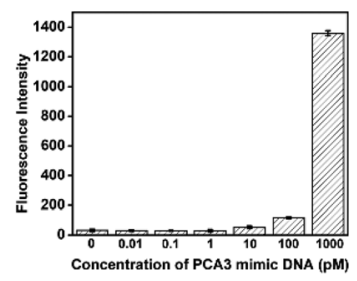

(B)

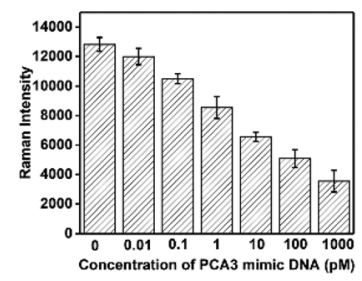

Fig. 5 Comparison of the assay results for different concentrations of PCA3 mimic DNA using (A) the reference (commercially available QuantiTTM PicoGreens dsDNA Assay Kit) method and (B) the proposed (SERSbased lateral flow assay) method. The error bars indicate the standard deviations calculated from five measurements. 
kit is estimated to be $10 \mathrm{pM}$, which is about 1000 times higher than that measured by the SERS-based competitive lateral flow assay developed by us. Furthermore, the assay time for the SERS-based competitive lateral flow assay $(15 \mathrm{~min})$ is much shorter than that of the commercial fluorescence kit (more than $1 \mathrm{~h}$ ). Thus, the one-step process of our assay is very simple and convenient.

\section{Conclusions}

In summary, we present a unique SERS-based competitive lateral flow assay for highly sensitive and rapid quantification of PCA3 mimic DNA. PCA3 is a newly discovered ideal biomarker for the diagnosis of prostate cancer. In this strategy, target PCA3 mimic DNA and reporter DNA conjugated SERS nanotags reacted competitively with capture DNA pre-immobilized on the test line. The quantitative evaluation of target PCA3 mimic DNA was successfully realized by monitoring the Raman peak intensity of SERS nanotags on the test line. To assess the sensitivity of the proposed SERS-based competitive lateral flow assay, the analytical performance was compared with that obtained using a commercially available fluorescence kit. According to the results, the LOD of our assay was estimated to be $3 \mathrm{fM}$, which is about three orders of magnitude more sensitive than that of the commercially available kit. Besides, our approach afforded a good linear relationship between the Raman intensity and the PCA3 mimic DNA concentration in a range of $0.01 \mathrm{pM}$ to $50000 \mathrm{pM}$. With the advantages of being simple, convenient, rapid and highly sensitive, the SERS-based competitive lateral flow platform will be a valuable tool for early genetic disease diagnosis.

\section{Conflicts of interest}

There are no conflicts to declare.

\section{Acknowledgements}

This project was supported by the National Natural Science Foundation of China (grant no. 21705139; 21575159; and 21778047), and the National Natural Science Foundation of Shandong Province in China (grant no. ZR2017BB026).

\section{References}

1 Y. Haga, M. Uemura, S. Baba, K. Inamura, K. Takeuchi, N. Nonomura and K. Ueda, Anal. Chem., 2019, 91(3), 22472254.

2 N. Dhenadhayalan, K. Yadav, M. I. Sriram, H. L. Lee and K. C. Lin, Nanoscale, 2017, 9(33), 12087-12095.

3 C. Y. Chen, X. H. Huang, Y. Wang, L. T. Lin, L. Liu, G. Y. Li, S. C. Wu, C. Z. Xu, J. H. Zhou and X. T. Shuai, RSC Adv., 2017, 7(18), 11057-11066.
4 S. Jiang, K. Zhang, Y. He, X. T. Xu, D. L. Li, S. P. Cheng and X. Zheng, RSC Adv., 2018, 8(5), 2768-2776.

5 J. D. Mangadlao, X. N. Wang, C. McCleese, M. Escamilla, G. Ramamurthy, Z. Wang, M. Govande, J. P. Basilion and C. Burda, ACS Nano, 2018, 12(4), 3714-3725.

6 A. Díaz-Fernández, R. Miranda-Castro, N. de-Los-SantosÁlvarez, E. F. Rodríguez and M. J. Lobo-Castañón, Biosens. Bioelectron., 2019, 128, 83-90.

7 D. Ilic, M. Djulbegovic, J. H. Jung, E. C. Hwang, Q. Zhou, A. Cleves, T. Agoritsas and P. Dahm, BMJ Open, 2018, 362, k3519.

8 C. H. Lin, H. W. Zhao, H. S. Zhao, Y. Y. Lu, J. T. Wu, Z. L. Gao, G. J. Li, Y. L. Zhang and K. Wang, Transl. Oncol., 2018, 11(3), 628-632.

9 J. Lai, L. Moya, J. An, A. Hoffman, S. Srinivasan, J. Panchadsaram, C. Walpole, J. L. Perry-Keene, S. Chambers, M. L. Lehman, C. C. Nelson, J. A. Clements and J. Batra, Sci. Rep., 2017, 7(1), 16862.

10 J. Tkac, V. Gajdosova, S. Hroncekova, T. Bertok, M. Hires, E. Jane, L. Lorencova and P. Kasak, Interface Focus, 2019, 9(2), 20180077.

11 Z. J. Mao, A. L. Ji, K. B. Yang, W. He, Y. F. Hu, Q. Zhang, D. H. Zhang and L. P. Xie, Medicine, 2018, 97(42), e12806.

12 K. P. P. Htoo, V. Yamkamon, S. Yainoy, T. Suksrichavalit, W. Viseshsindh and W. Eiamphungporn, Clin. Chim. Acta, 2019, 488, 40-49.

13 U. H. Frey, H. S. Bachmann, J. Peters and W. Siffert, Nat. Protoc., 2008, 3(8), 1312-1317.

14 M. S. Malnati, G. Scarlatti, F. Gatto, F. Salvatori, G. Cassina, T. Rutigliano, R. Volpi and P. Lusso, Nat. Protoc., 2008, 3(7), 1240-1248.

15 D. Jungkind, J. Clin. Virol., 2001, 20, 1-6.

16 S. Park, Y. Zhang, S. Lin, T. H. Wang and S. Yang, Biotechnol. Adv., 2011, 29, 830-839.

17 P. Klapper, D. Jungkind, T. Fenner, R. Antinozzi, J. Schirm and C. Blanckmeister, Clin. Chem., 1998, 44, 1737-1739.

18 R. Liao, K. He, C. Y. Chen, C. Q. Cai and X. M. Chen, Anal. Chem., 2016, 88(8), 4254-4258.

19 R. Higuchi, G. Dollinger, P. S. Walsh and R. Griffith, Nat. Biotechnol., 1992, 10, 413-417.

20 H. H. Wang, H. Wang, X. R. Duan, Y. Y. Sun, X. D. Wang and Z. P. Li, Chem. Sci., 2017, 8, 3635-3640.

21 D. Pan, L. J. Mi, Q. Huang, J. Hu and C. H. Fan, Integr. Biol., 2012, 4, 1155-1163.

22 R. M. Pallares, L. Sutarlie, N. T. K. Thanh and X. D. Su, Sens. Actuators, B, 2018, 271, 97-103.

23 Y. Teng, H. Tateishi-Karimata, T. Tsuruoka and N. Sugimoto, Molecules, 2018, 23(11), 2889.

24 E. O. Blair and D. K. Corrigan, Biosens. Bioelectron., 2019, 134, 57-67.

25 K. L. Untiveros, E. G. da Silva, F. C. de Abreu, E. F. da Silva, J. X. de Araujo, T. M. de Aquino, S. M. Armas, R. O. de Moura, F. J. B. Mendonca, V. L. Serafim and K. ChumbimuniTorres, Biosens. Bioelectron., 2019, 133, 160-168.

26 J. Yu, J. Jeon, N. Choi, J. O. Lee, Y. P. Kim and J. Choo, Sens. Actuators, B, 2017, 251, 302-309. 
27 M. L. You, M. Lin, Y. Gong, S. R. Wang, A. Li, L. Y. Ji, H. X. Zhao, K. Ling, T. Wen, Y. Huang, D. F. Gao, Q. Ma, T. Z. Wang, A. Q. Ma, X. L. Li and F. Xu, ACS Nano, 2017, 11(6), 6261-6270.

28 I. V. Safenkova, V. G. Panferov, N. A. Panferova, Y. A. Varitsev, A. V. Zherdev and B. B. Dzantiev, Talanta, 2019, 195, 739-744.

29 M. Kong, J. H. Shin, S. Heu, J. K. Park and S. Ryu, Biosens. Bioelectron., 2017, 96, 173-177.

30 Y. M. Shen and G. Y. Shen, ACS Omega, 2019, 4(3), 50835087.

31 Z. Yang, C. Yi, S. J. Lv, Y. H. Sheng, W. Wen, X. H. Zhang and S. F. Wang, Sens. Actuators, B, 2019, 285, 326-332.

32 Y. Gao, Z. Y. Zhu, X. X. Xi, T. W. Cao, W. Wen, X. H. Zhang and S. F. Wang, Biosens. Bioelectron., 2019, 133, 177-182.

33 Z. Rong, R. Xiao, S. Xing, G. L. Xiong, Z. Y. Yu, L. M. Wang, X. F. Jia, K. L. Wang, Y. W. Cong and S. Q. Wang, Analyst, 2018, 143(9), 2115-2121.

34 L. K. Lin and L. A. Stanciu, Bisphenol, Sens. Actuators, B, 2018, 276, 222-229.

35 S. Tian, O. Neumann, M. J. McClain, X. Yang, L. N. Zhou, C. Zhang, P. Nordlander and N. J. Halas, Nano Lett., 2017, 17(8), 5071-5077.

36 X. L. Fu, L. X. Chen and J. Choo, Anal. Chem., 2017, 89(1), 124-137.

37 R. Wang, K. Kim, N. Choi, X. Wang, J. Lee, J. H. Jeon, G. E. Rhie and J. Choo, Sens. Actuators, B, 2018, 270, 72-79.
38 X. L. Fu, Y. Q. Wang, Y. M. Liu, H. T. Liu, L. W. Fu, J. H. Wen, J. W. Li, P. H. Wei and L. X. Chen, Analyst, 2019, 144, 1582-1589.

39 W. Ren, Y. Fang and E. Wang, ACS Nano, 2011, 5, 64256433.

40 X. L. Zhang, X. H. Xiao, Z. G. Dai, W. Wu, X. G. Zhang, L. Fu and C. Z. Jiang, Nanoscale, 2017, 9(9), 31143120.

41 J. J. Yu, M. Z. Shen, S. Y. Liu, F. Li, D. P. Sun and T. H. Wang, Appl. Surf. Sci., 2017, 406, 285-293.

42 M. I. Dar, S. Sampath and S. A. Shivashankar, J. Mater. Chem., 2012, 22(42), 22418-22423.

43 B. W. Zhao, S. L. Feng, Y. X. Hu, S. Wang and X. N. Lu, Food Chem., 2019, 276, 366-375.

44 J. A. Sioss, R. B. Bhiladvala, W. H. Pan, M. W. Li, S. Patrick, P. Xin, S. L. Dean, C. D. Keating, T. S. Mayer and G. A. Clawson, Nanomedicine, 2012, 8(6), 1017-1025.

45 N. G. Bastus, J. Comenge and V. Puntes, Langmuir, 2011, 27(17), 11098-11105.

46 W. N. Leng and P. J. Vikesland, Anal. Chem., 2013, 85(3), 1342-1349.

47 B. Yurke, A. J. Turberfield, A. P. Mills Jr., F. C. Simmel and J. L. Neumann, Nature, 2000, 406, 605-608.

48 J. H. Chen, S. G. Zhou and J. L. Wen, Anal. Chem., 2014, 86, 3108-3114.

49 J. H. Cho, S. M. Han, E. H. Paek, I. H. Cho and S. H. Paek, Anal. Chem., 2006, 78, 793-800. 